\title{
Reflections on Inter-University Collaboration to Deliver a Graduate Certificate in Evaluation to Government of the Northwest Territories Employees
}

\author{
James McDavid \\ University of Victoria \\ Robert Shepherd \\ Carleton University \\ Sahara Morin \\ Government of the Northwest Territories
}

\begin{abstract}
This practice note describes and reflects on an inter-university collaboration to deliver a graduate credential in evaluation to Government of the Northwest Territories (GNWT) staff. The collaboration involved faculty members from two member institutions of the Consortium of Universities for Evaluation Education (CUEE). We describe the process of negotiating a contractual agreement, developing and delivering the program, and offer our reflections and lessons learned. Overall, this sort of collaboration is worthwhile but is challenging to implement in conditions where universities encourage student movement across institutional boundaries but, at the same time, are much less supportive of program to program collaborations across these boundaries.
\end{abstract}

Keywords: collaboration, graduate evaluation education, professional development

Résumé : La présente note sur la pratique décrit et analyse une collaboration interuniversitaire visant à offrir un diplôme supérieur en évaluation au gouvernement des Territoires $d u$ Nord-Ouest. Des professeurs de deux institutions membres $d u$ Consortium des universités pour l'enseignement de l'évaluation (CUEE) ont travaillé ensemble sur ce projet. Nous décrivons le processus de négociation d'une entente contractuelle, ainsi que la conception et la prestation du programme, et offrons nos réflexions et les leçons tirées de l'initiative. Dans l'ensemble, ce type de collaboration en vaut la peine, mais est difficile à mettre en cuvre dans des conditions où les universités encouragent la mobilité étudiante au-delà de frontières institutionnelles, mais, en même temps, nappuient pas énormément les collaborations entre les programmes de différents établissements.

Mots clés : collaboration, formation supérieure en évaluation, perfectionnement professionnel

Corresponding author: James McDavid, School of Public Administration, University of Victoria, PO Box 1700 STN CSC, Victoria, BC, V8W 2Y2; jmcdavid@uvic.ca

(c) 2020 Canadian Journal of Program Evaluation / La Revue canadienne d'évaluation de programme 35.1 (Spring / Printemps), 104-110 doi: 10.3138/cjpe.56949 
This practice note describes and reflects on a collaboration between faculty members in two Canadian universities to design and deliver a credit Graduate Certificate in Program Evaluation to a cohort of Government of the Northwest Territories (GNWT) employees. Both partners are members of the Consortium of Universities for Evaluation Education (CUEE), a voluntary organization of universities across Canada created in 2008 to advance opportunities for students to pursue graduate education in evaluation in Canadian universities.

\section{BACKGROUND TO THE COLLABORATION}

The GNWT has invested in internal evaluation capacity and professional training for some time at various expertise levels. In addition to short-term training opportunities that are offered throughout the year, the GNWT sought a more in-depth credential-based training program for staff who were interested in both conducting internal evaluations and working toward earning the Credentialed Evaluator (CE) designation by the Canadian Evaluation Society (CES). In 2004, the GNWT contracted with the University of Melbourne to design and deliver a Graduate Certificate in Evaluation and Assessment that proved successful in training 19 of 21 participants. Since that program was offered, the GNWT has wanted something similar but with improved online resources and support.

The GNWT specified four requirements in a prospective program: it must be available primarily online; each course would be supported by at least two days of in-person instruction; each student would design and complete an evaluation project from start to finish; and it must be delivered with a public-sector focus. To facilitate such a program, three universities with desirable graduate-level programs were approached simultaneously to explore potential opportunities that would meet GNWT interests; Carleton University, the University of Victoria (UVic), and Claremont Graduate University. At the time, each program offered unique aspects of interest to the GNWT, though none encompassed every desired aspect on its own. Robert Shepherd (Carleton), the former Chair of the CUEE and supervisor of the Carleton diploma, approached Jim McDavid (School of Public Administration at the University of Victoria) to determine whether there was interest in collaborating on this project given that the UVic Graduate Certificate in Evaluation Program was available online and the potential existed for both programs to be adapted.

Several considerations were important in negotiating an agreement to design and deliver the program. The most important of these was designing a program that met the needs of the GNWT, received senior management support, and served as a framework for negotiating the specifics of an agreement and the associated logistics between Carleton and UVic. Time was also needed to design the program. Negotiations with the GNWT began in the spring of 2014, with a preferred start date of January 2015. Several moving parts were put into motion in parallel: while program design work proceeded between the two partners, contract negotiations with the GNWT occurred at the same time. 
A second consideration was where to house the program-UVic or Carleton. Because Carleton's diploma was a six-course program and tuition was higher, a decision was made to make UVic the institutional home.

A third issue was whether the partnership would formally acknowledge the two institutional units that housed the Carleton and UVic programs. Ultimately, a formal partnership between the two universities could not be realized, which uncovered significant barriers worth noting.

\section{PROGRAM DESIGN AND STUDENT ADMISSIONS}

To meet the needs of the GNWT, the program had to be flexible and not overly taxing on full-time GNWT employees. It was decided that the program should follow the UVic four-course sequence rather than Carleton's six-course sequence, and that content should have a northern, public-sector focus. This meant that elements of both programs had to be incorporated into the design. Robert Shepherd and Jim McDavid spent several days together at Carleton in the fall of 2014 to work out the program's design and create several videos to introduce the program and the contents of each of the four courses. At the same time, Sahara Morin, Program Review Analyst in the GNWT, solicited interest from prospective students across the government. A total of 23 applications were considered for a preliminary review, and all 23 applicants were encouraged to apply to the UVic Faculty of Graduate Studies as regular Graduate Certificate in Evaluation students.

\section{PROGRAM DELIVERY}

\section{Course Sequence and Approach}

The program started in January 2015. Each of the four courses had at least one two-day face-to-face module complemented by online modules before and after that class time. The first course introduced participants to the field, examined various schools of thought in evaluation, and assisted students in preparing an evaluation plan. In the first course, there were weekly video lectures to accompany the readings and the online work. The second course (September 2015) focused on qualitative methods, and the third course (January 2016) examined quantitative methods in evaluation. The final course was delivered in September 2016 and consisted of three two-day in-person sessions in Yellowknife. It focused on analysis of data, coming to findings, and creating effective reports and presentations.

A hybrid approach was used in every course, whereby participants would review course content and participate weekly via online discussion posts. Participants in the program were expected to complete an actual evaluation project with a real client, and content supporting this work was built into each course. Our in-person sessions focused mainly on project-related knowledge and skills and in small-group tutorials dealt with issues as they arose. There were nine evaluation projects that assessed various environmental programs, education initiatives, local 
programs such as drop-in centres, lending programs, and large governmental initiatives. Of the 23 participants who started the program, 16 finished on schedule, and two more completed on an individualized basis.

\section{Working through the evaluation projects}

Because the student teams were working on a wide range of evaluation projects from the first course at different paces, it was challenging to keep everyone working in unison. Some teams advanced in their courses and projects quickly, while others did not make as much progress and incorporated course content as their projects progressed. This made program design and management challenging, as it meant that the instructors had to monitor progress regularly and adjust course content as needs arose. Both instructors worked intensively with teams in the face-to-face sessions of the fourth course especially to bring them to a point where they were all drafting their reports by October 2016. The final session in December was designated for report presentations, and evaluation clients were invited to the sessions, including several deputy ministers. Participants presented their findings and recommendations, lessons learned, or considerations for the future of the program, and a week later they submitted their final reports to the course instructors for grading.

During the final session of the course, students were invited to offer feedback on the course and the program. Participants made several observations and offered an important insight. Given heavy reliance on completion of an evaluation project, it was suggested that the first course should have been offered in September 2015 rather than January 2015, to better align with the work schedules of clients. The second course, offered in January, should have focused on methods for measuring and collecting both qualitative and quantitative lines of evidence, as many project teams were ready for these activities by this point. The third course (the following September) would combine qualitative and quantitative data analysis methods, to ensure steady progress on the projects. By the following January term, the final course would focus on coming to findings and report drafting, with presentations to clients by the spring. This sequence would have shortened the program by one semester.

\section{REFLECTIONS ON THIS INTER-INSTITUTIONAL COLLABORATION}

Both university partners discovered how challenging it is to work across institutional boundaries. One important boundary involved administrative obstacles between a university and non-university entity. At UVic, there were very few previous examples of combining graduate credit education with professional development. Most notably, professional development is generally considered to be a non-credit activity and therefore not linked to the university's main mission. After several options had been canvassed, an educational services agreement was struck that outlined the program content and the delivery model and included arrangements to pay the tuition fees for the students in the program and program design 
and delivery expenses via a contract with the University of Victoria. Administration of the program within the GNWT also presented risks to the sponsoring department (Finance) and challenges to administer within the regulatory financial framework to which GNWT departments are bound. Fortunately, UVic was willing to work with the Program Review Office to accommodate administrative requirements whenever possible, thereby reducing the Department of Finance's risks, specifically related to bearing the financial burden for students who might prematurely withdraw from the program without having recouped the tuition costs from their home department.

A second boundary involved coming to an agreement between universities. The two universities could not come to agreement for several reasons. First, the collaboration was regarded by Carleton as a professional contract and not an approved degree. Given the time available, it was not practical to secure Senate approval for a new program to match the UVic Graduate Certificate. Second, after several consultations with senior university officials, management responsibility could not be agreed upon in the time available. Third, formally accommodating a joint offering was regarded as a tax on existing course loads for Carleton faculty. This meant that as long as the arrangement was labelled a professional one, the courses offered were considered to be above load, with no possibility for accommodation. That said, although there was general support for the initiative at Carleton, there was little encouragement to formally collaborate in this manner without going through an institutional recognition process for the degree.

\section{LESSONS LEARNED}

Based on the experiences from this collaboration, there are several observations and lessons learned.

First, it is essential to have an academic champion in each of the institutions. The UVic academic lead was involved in all phases of the project: designing the program, writing the Educational Services Agreement between UVic and GNWT, preparing sub-contracts, working with the Faculty of Graduate Studies and with Graduate Admissions to process student applications, keeping track of student academic progress, and serving as a de facto graduate advisor for the program across all four courses.

Second, the Educational Services Agreement facilitated collaboration in the design of the program and in its delivery-principally a travel budget that was sufficient to ensure instructor coverage for all the face-to-face sessions in Yellowknife. For the students in the program, the face-to-face sessions were an integral part of the program and provided several opportunities for people to get to know each other who otherwise would not have had such contact outside of Yellowknife.

Third, this collaboration and others like it combine graduate credit education and professional development. Although students in the program were expected to meet the academic standards of the hosting university, being available for them for consultations, advice, and in some cases counselling was essential. Both 
Rob Shepherd and Jim McDavid committed themselves to being available for the student project teams across all four semesters of the program. Even when other faculty members were involved as instructors, the students could come to either Rob or Jim with questions about their projects and how those projects fitted into the courses.

Fourth, given that territorial governments in particular have little experience with formal degree training for their employees, it was important for each of the partners to be present and visible in the program and its management. Although much of the routine degree management was conducted through UVic, it was important to build confidence with the GNWT partner that both the credential itself and the students were being well supervised in their studies. It was also essential to have a GNWT secretariat to ensure that any contract, or student issues, could be addressed with on-site support. The GNWT secretariat, Sahara Morin, acted as liaison in many ways, not only with travel and classroom arrangements but also with managing student expectations, communicating program requirements, and navigating the internal financial administration involved with such a large contract and several participating departments on a charge-back model. Having a key GNWT contact to maintain and update senior management on the effectiveness of the arrangement and advancement of students through the program was critical to program success.

\section{CONCLUDING THOUGHTS}

Creating this evaluation certificate with the GNWT was an experiment in governance between two participating CUEE institutions, as well as an exploration of the viability and effectiveness of offering credit-based graduate level programming as a means of professional development to public-sector employees. As a first attempt, it was not entirely successful from an internal perspective. Outwardly, the program enjoyed great success, due in large part to the commitment of the instructors, the GNWT secretariat, and senior officials in the GNWT. Managing and delivering this program was time- and effort-intensive, particularly in the initial stages. Should this program be repeated, it is important to ensure there is commitment from the respective institutions and time to negotiate the rulesladen bureaucratic processes that may be unique to each.

The actual work of delivering the program is not unlike any other degree program, except that the students have more specific and particular interests and objectives. In this case, all of the participants were resident in the NWT and came from different departments with sometimes disparate priorities. Nevertheless, such interests made for a valuable learning opportunity both for the instructors on the inner workings of a bureaucracy as well as for staff from various departments.

Working through different ontological and epistemological perspectives regarding course and program content was also a challenge, but it was still a rare opportunity between colleagues. The conversations were often passionate and, had we been thinking, should have been recorded and shared with the students. 
Advancing evaluation training practice is also a core objective of the CUEE, one that is often not pursued as vigorously as it could be.

Should the opportunity arise again to deliver such a program, despite all of the challenges, this kind of project is worth the effort. It is rare to see firsthand the product of one's training efforts. With capacity building at such a premium, especially in territorial governments, such programs are important in meeting the specific needs of those governments. The challenge for universities in the future will be to embrace these needs, not to regard them as administrative problems to overcome.

\section{AUTHOR INFORMATION}

James McDavid is professor emeritus in the School of Public Administration at the University of Victoria. He has conducted research and program evaluations focusing on federal, state, provincial, and local governments in the United States and Canada. His recent published research focuses on teaching evaluation and the prospects for professionalizing the field. The third edition of his textbook, Program Evaluation and Performance Measurement: An Introduction to Practice, was published by Sage Publications in 2019.

Robert Shepherd is associate professor in the School of Public Policy \& Administration at Carleton University. He is supervisor of the online graduate diploma in public policy and program evaluation. At present, he is a principal researcher on the Indigenous Youth Futures Project in Northwestern Ontario. His research currently focuses on applying evaluation practice in Indigenous developmental contexts with a focus on youth programs and resilience efforts.

Sahara Morin began her career in evaluation and performance measurement with the Government of the Northwest Territories in 2004. From 2004 to 2017, Sahara held progressively senior roles in central agency departments responsible for government-wide guidance, support, and oversight in the areas of program research, analysis, evaluation, and business planning. Sahara has been a vocal advocate for evidence-based decision making, for which a corporate culture of periodic evaluation and ongoing program monitoring is critical. 